\title{
PERBAIKAN WAKTU DENGUNG RUANG KULIAH DENGAN OPTIMALISASI MODEL RUANGAN DAN JENIS MATERIAL
}

\author{
Yunita Ardianti Sabtalistia \\ Dosen Prodi S1 Arsitektur, Fak. Arsitektur dan Perencanaan, UNTAR Jakarta \\ e-mail: yunitas@ft.untar.ac.id
}

\begin{abstract}
ABSTRAK
Kegiatan belajar-mengajar di ruang kuliah bisa berjalan dengan baik jika suara dari dosen bisa terdengar dengan jelas ke telinga mahasiswa. Salah satu parameter akustik agar pembicaraan dalam ruangan bisa jelas terdengar adalah waktu dengung (Reverberation Time). Jika waktu dengung terlalu panjang maka isi pembicaraan menjadi tidak jelas karena suara sumber bunyi akan semakin lama sampai ke telinga penerima bunyi. Bentuk elemen interior, luas permukaan, dan jenis material dalam suatu ruangan menentukan tinggi rendahnya waktu dengung. Tujuan penelitian ini adalah menemukan model ruangan kuliah yang mempunyai waktu dengung paling optimal ditinjau dari bentuk plafond, bentuk dinding, dan jenis material plafond dan dinding. Ruang kuliah Wastu 1 dengan kapasitas 144 kursi yang berada di Universitas Tarumanagara dijadikan sampel penelitian. Penentuan jenis material dan model ruangan kondisi eksisting berdasarkan hasil survei dan pengukuran di ruang Wastu 1. Selanjutnya dengan menggunakan software Ecotect, model plafond dan dinding dieksperimen sebanyak 4 kali dengan jenis material yang sudah ditentukan untuk mengetahui berapa waktu dengungnya. Hasil perhitungan $R T$ pada model eksisting dan model eksperimen dibandingkan dengan RT optimal untuk ruangan kuliah. Hasil penelitian ini menunjukkan bahwa model plafond datar dengan material gypsum dan acoustic dan penambahan lapisan cork pada kolom dan dinding paling mampu mendekati RT optimal.
\end{abstract}

\section{Kata kunci : Bentuk Dinding, Bentuk Plafond, Jenis Material, Ruang Kuliah, Waktu Dengung.}

\section{PENDAHULUAN}

Waktu dengung (Reverberation Time/RT) adalah waktu yang diperlukan agar bunyi bisa meluruh dari $60 \mathrm{~dB}$ sampai $0 \mathrm{~dB}$ yang dihitung dengan satuan detik (Templeton, 1997:53). Semakin panjang waktu dengung maka isi pembicaraan di dalam suatu ruangan menjadi tidak jelas. Ruangan yang mempunyai aktivitas pembicaraan (speech), seperti: ruangan kelas, kuliah, auditorium, dsb membutuhkan waktu dengung berkisar 0,6 0,8 detik (Doelle, 1986:87). 
Penelitian Kurniasih, 2018 membuktikan bahwa penggunaan kain berpori, screen, styrofoam, dan karpet pada dinding, plafond, dan lantai Gedung Balai Sarbini menyebabkan gedung tersebut hanya cocok digunakan untuk ruang konvensi dan ruang kuliah tetapi tidak cocok digunakan untuk ruang konser. Penggunaan material-material berpori tersebut menyebabkan nilai RT menjadi 0,6-0,7 detik padahal RT optimal untuk ruang konser adalah 1,5-2,1 detik (Kurniasih, 2018:90).

Salah satu elemen interior yang mempunyai luas permukaan yang cukup luas adalah plafond. Penelitian Sabtalistia, 2016 membuktikan bahwa bentuk plafond yang paling mengoptimalkan RT ruangan kelas adalah plafond lengkung. Kelengkungan pada sudut-sudut plafond lengkung dapat mengurangi volume suatu ruangan sehingga dapat memperpendek waktu dengung. Hal itu yang menyebabkan waktu dengung pada ruangan dengan plafond lengkung paling mendekati RT optimal untuk ruangan kelas $(0,61$ detik) (Sabtalistia, 2016:39).

Korden merupakan jenis material yang mempunyai nilai a yang cukup tinggi. Ruang Auditorium Fakultas Kedokteran UGM mempunyai korden sedang $0,48 \mathrm{~kg} / \mathrm{m}^{2}$ dengan nilai $\alpha$ sebesar 0,49 pada frekuensi $500 \mathrm{~Hz}$ dan 0,75 pada frekuensi $1000 \mathrm{~Hz}$ (Ola, F.B, 2015:99). Hasil penelitian Ola, 2015 membuktikan bahwa penggunaan korden lebih bisa mengurangi nilai RT secara signifikan terhadap pengurangan nilai RT daripada penambahan jumlah penonton (audian). Nilai RT terendah diperoleh saat korden terpasang $100 \%$ dan jumlah audian berkurang $50 \%$. Saat audian $100 \%$ dan korden tidak terpasang $(0 \%)$ ternyata tidak terlalu mampu menurunkan nilai RT.

Jumlah penonton atau penghuni yang ada di dalam suatu ruangan mempengaruhi tinggi rendahnya waktu dengung. Penonton yang duduk di kursi kulit, penonton yang berdiri, dan penonton yang duduk di kursi kayu mempunyai nilai $\alpha$ yang berbeda-beda. Nilai $\alpha$ pada penonton yang duduk di kursi kayu sebesar 0.56 , penonton yang berdiri sebesar 0.42 , dan penonton yang duduk di kursi kulit sebesar 0.58 pada frekuensi $500 \mathrm{~Hz}$ (Templeton, 2001:52). Penonton yang duduk di kursi yang lebih berpori dan empuk mempunyai nilai a lebih tinggi. Penonton sebanyak 1000 orang pada gedung balai Sarbini menyebabkan ruangan mempunyai waktu dengung sebesar 0,6 detik. Pada saat balai Sarbini tidak ada penonton mempunyai nilai RT 0,1 detik lebih tinggi daripada saat ada 1000 penonton (Kurniasih, 2018:90).

Ruangan kuliah merupakan ruangan kelas untuk mahasiswa di Universitas atau Sekolah Tinggi. Ruang kuliah mempunyai fungsi kegiatan pembicaraan (speech) sehingga waktu dengung optimal ruangan kuliah berkisar 0.6-0.8 detik. Waktu dengung ruang kuliah yang sesuai dapat meningkatkan kualitas kegiatan belajar-mengajar karena isi pembicaraan dosen dapat jelas terdengar oleh mahasiswa.

PAWON: Jurnal Arsitektur, Nomor 01 Volume IV, Januari-Juni 2020, ISSN 2597-7636 
Tujuan penelitian ini adalah mengetahui model ruangan kuliah yang mempunyai waktu dengung yang sesuai dengan standard waktu dengung untuk speech. Model ruangan ditinjau dari bentuk dan material dinding dan bentuk plafond.

\section{TINJAUAN PUSTAKA}

Waktu dengung adalah waktu yang dibutuhkan apabila suara melemah (decay) dalam $60 \mathrm{~dB}$ dalam suatu ruang tertutup (Kurniasih, 2018:37). Faktor yang mempengaruhi RT adalah volume ruang (V), kapasitas penonton, serta bidang lingkup yang absorbtif / reflektif (A). Rumus 1 dan 2 adalah rumus perhitungan RT berdasarkan perhitungan Sabine. Satuan RT adalah detik (Kurniasih, 2018:37).

$$
\begin{aligned}
& \mathbf{R T}_{60}=0.161 \mathrm{~V} / \mathrm{S} \bar{\alpha} \\
& \bar{\alpha}=\frac{\sum_{\mathrm{i}=1}^{\mathrm{n}} \mathbf{S}_{\mathrm{i} \alpha_{1}}}{\sum_{\mathrm{i}=1}^{\mathrm{n}} \mathbf{S}_{\mathrm{i}}}
\end{aligned}
$$

\footnotetext{
Keterangan:

RT60 : Waktu dengung (Reverberation Time), detik

$\mathrm{V} \quad$ : Volume ruangan, $\mathrm{m}^{3}$

a : Koefisien penyerapan (absorbsi) bunyi

$\bar{\alpha} \quad$ : Nilai rata-rata koefisien absorbsi bunyi pada seluruh luas area yang terekspos

$\mathrm{S} \quad$ : Luas area permukaan yang terekspos, $\mathrm{m}^{2}$
}

Standard waktu dengung pada ruang kelas yang baik berkisar antara 0,6 - 0,8 detik pada frekuensi menengah $(500 \mathrm{~Hz})$ (Doelle, 1986:87). Nilai tersebut bergantung pada volume dengan kondisi ruang sedang dipakai beserta perabotnya (Doelle, 1986:87). Waktu dengung optimal dapat dapat dihitung dengan persamaaan sebagai berikut (McMullan, 2007:225).

$$
\mathbf{t}=\mathbf{r}(0.0118 \sqrt[3]{\mathbf{v}}+\mathbf{0 . 1 0 7})
$$

Keterangan:

t : Waktu dengung optimal, detik

$\mathrm{V}$ : Volume ruangan, $\mathrm{m}^{3}$

$r$ : 2 untuk pembicaraan, 5 untuk orkestra, 6 untuk paduan suara 
Berdasarkan rumus RT, waktu dengung dipengaruhi oleh koefisien penyerapan bunyi (absorbs) bunyi ( $\alpha$ ). Semakin tinggi a maka semakin besar material tersebut menyerap bunyi sehingga dapat mengurangi nilai RT. Begitu pula sebaliknya. Berdasarkan persamaan 3, waktu dengung optimal tergantung pada jenis aktivitas dalam ruangan tersebut. Untuk fungsi pembicaraan, waktu dengung yang dibutuhkan lebih pendek. Pada gedung konser waktu dengung yang dibutuhkan bisa lebih panjang karena dipakai untuk fungsi orkestra dan paduan suara.

\section{METODE PENELITIAN}

Metode yang digunakan adalah metode eksperimen. Alat bantu eksperimen penelitian ini menggunakan Autodesk Ecotect Analysis 2011. Metode eksperimen lebih berfokus pada hubungan sebab-akibat (Groat dkk, 2002). Perubahan model plafond, model dinding, dan jenis material plafond dan dinding menjadi penyebab sedangkan waktu dengung menjadi akibat. Hasil eksperimen adalah model ruangan kuliah beserta jenis materialnya yang paling baik dan yang terburuk berdasarkan waktu dengung optimal untuk ruangan kuliah.

Sampel penelitian ruangan kuliah adalah ruang Wastu 1 yang merupakan ruang kuliah mahasiswa Jurusan Arsitektur yang berada di lantai 8, Gedung K, Kampus 1, Universitas Tarumanagara, Jakarta Barat. Ruang Wastu 1 merupakan ruang kuliah dengan kapasitas 144 kursi dan mempunyai luas area sebesar $170,375 \mathrm{~m}^{2}$ (Gambar 1). Ruang kuliah ini mempunyai volume besar karena ketinggian plafon yang cukup tinggi. Kursi yang ada di ruangan tersebut mempunyai penutup kursi dari bahan textile. Balok lantai menggunakan baja WF yang terekspos dan balok beton.

Model plafond dan model dinding beserta jenis materialnya akan dieksperimen dengan menggunakan Ecotect. Eksperimen dilakukan sebanyak 5 kali, yaitu: 1 kali untuk model eksisting dan 4 kali untuk model eksperimen yang diusulkan.
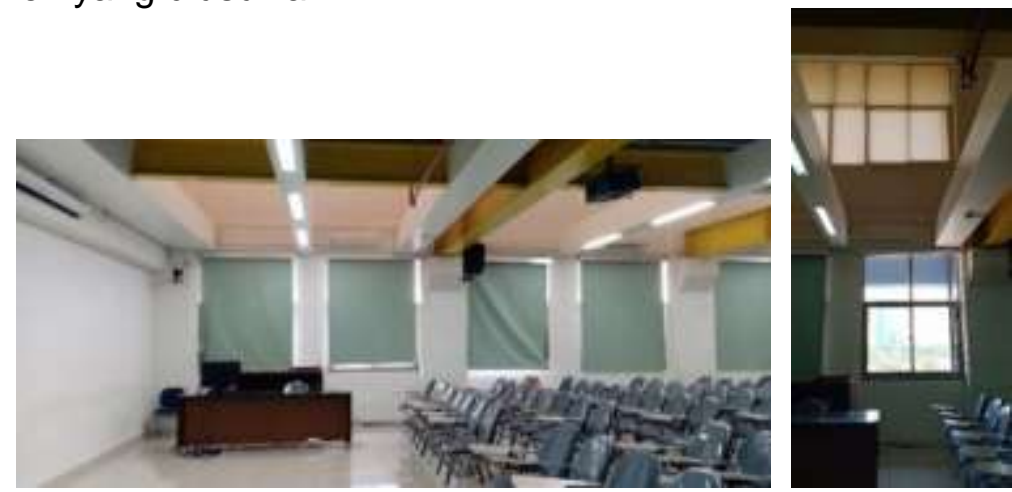

Gambar 1.

Ruang Wastu 1, Universitas Tarumanagara Sumber: Survei. Agustus 2019

PAWON: Jurnal Arsitektur, Nomor 01 Volume IV, Januari-Juni 2020, ISSN 2597-7636 


\section{HASIL DAN PEMBAHASAN}

\subsection{KONDISI EKSISTING}

Simulasi Ecotect digunakan untuk mensimulasikan model ruangan sehingga dapat diketahui waktu dengungnya. Tahap awal adalah dengan membuat model ruangan sesuai dengan kondisi eksisting berdasarkan gambar denah dan potongan (Gambar 2,3, dan 4). Bagian depan ruang kelas terdapat dinding brick plaster, meja presentasi, lemari, dan papan tulis (Gambar 5). Bagian belakang ruang kelas terdapat dinding brick plaster, kaca jendela single glass, dan pintu geser dari kayu solid (Gambar 6).

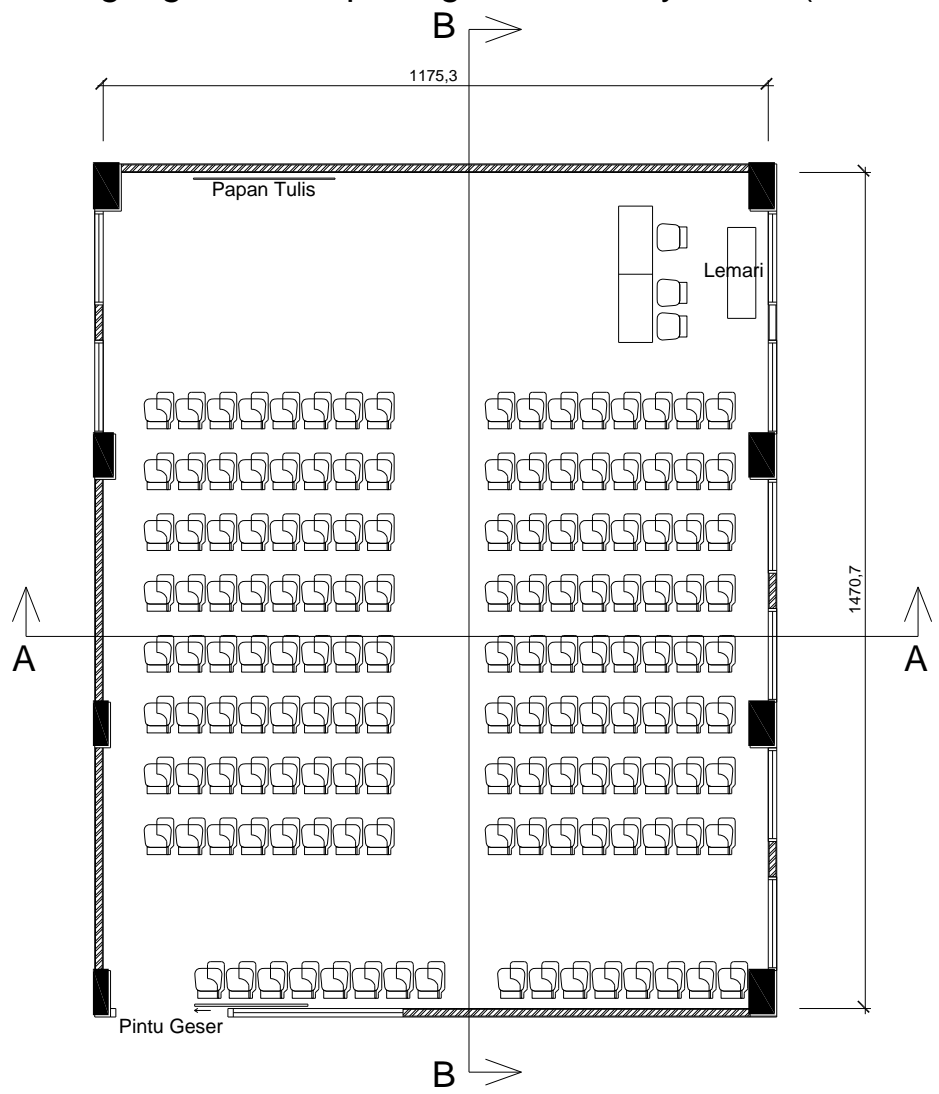

Gambar 2.

Denah Sampel Penelitian (Scale to Fit)

Sumber: Hasil Pengukuran, November 2019

Material pada elemen bangunan kondisi eksisting disimulasikan ke dalam Ecotect berdasarkan hasil survei (Tabel 1). Jumlah kursi yang ada di ruang Wastu 1 sebanyak 144 kursi (Gambar 2). Pada saat kegiatan kuliah sangat jarang sekali kursi penuh terisi. Oleh karena itu jumlah kursi diasumsikan $80 \%$ saja yang berpenghuni. Jadi jumlah kursi yang berpenghuni hanya 115 kursi. 


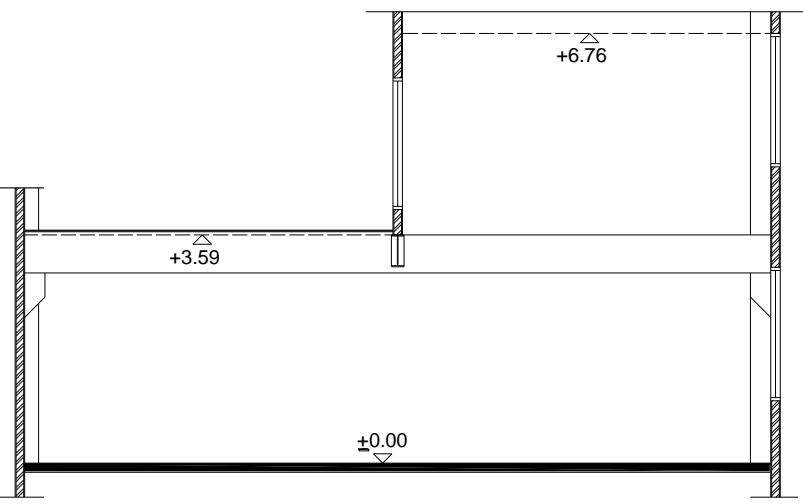

Gambar 3.

Potongan A-A Sampel Penelitian (Scale to Fit) Sumber: Hasil Pengukuran, November 2019

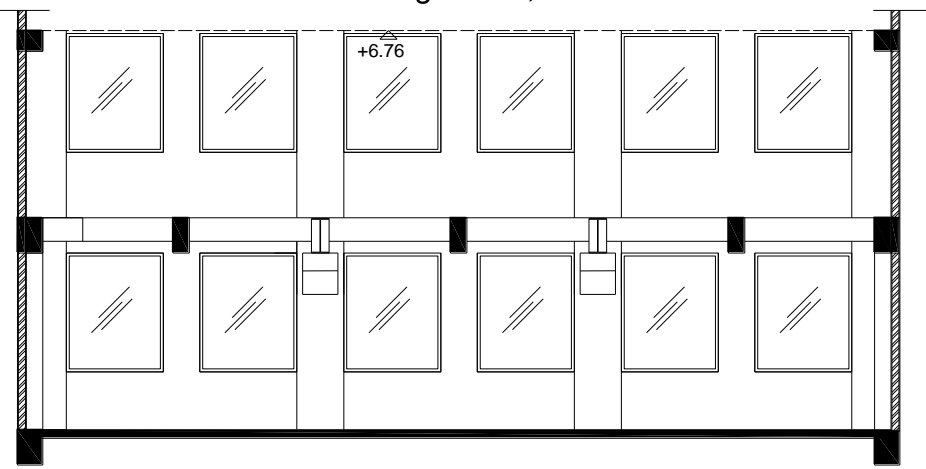

Gambar 4.

Potongan B-B Sampel Penelitian (Scale to Fit)

Sumber: Hasil Pengukuran, November 2019

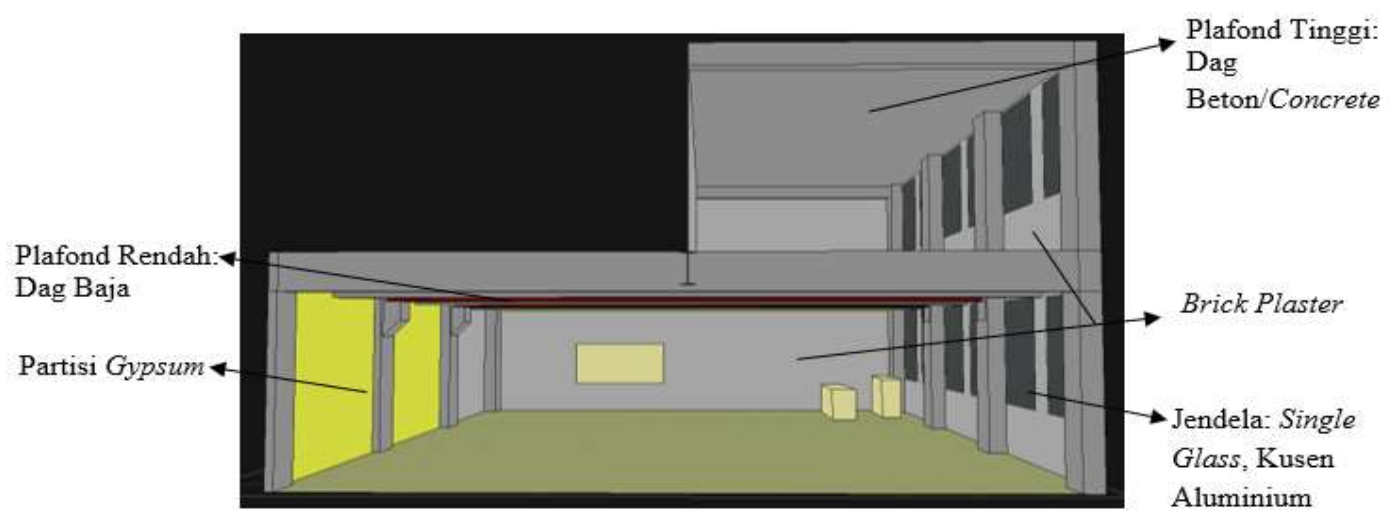

Gambar 5.

Modelling Bagian Depan Ruangan Kuliah

Sumber: Ecotect, November 2019

PAWON: Jurnal Arsitektur, Nomor 01 Volume IV, Januari-Juni 2020, ISSN 2597-7636 


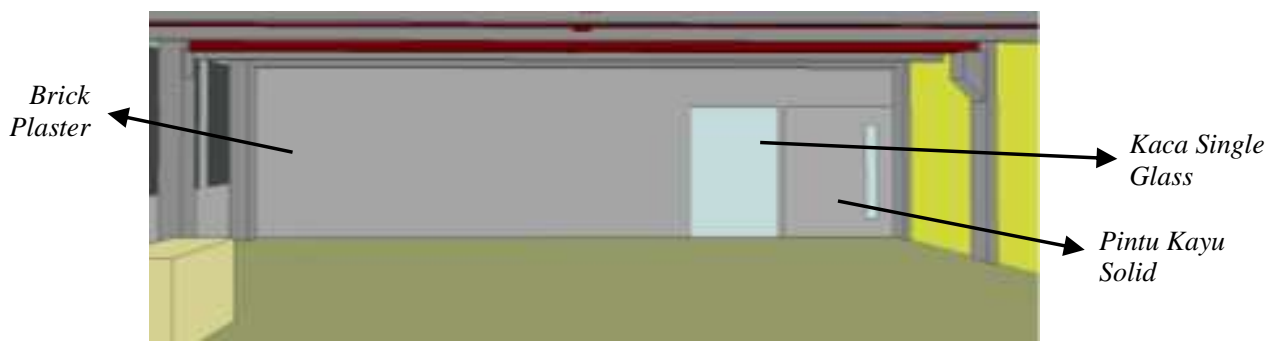

Gambar 6.

Modelling Bagian Belakang Ruangan Kuliah

Sumber: Ecotect, November 2019

Tabel 1.

Material Properties pada Kondisi Eksisting

\begin{tabular}{lllc} 
No & Elemen Ruangan & \multicolumn{1}{c}{ Jenis Material } & $\begin{array}{c}\alpha \text { pada Frekuensi } \\
\mathbf{5 0 0 ~} \mathbf{~} z\end{array}$ \\
\hline 1 & Dinding 1 & Brick Plaster & 0,02 \\
\hline 2 & Dinding 2 & $\begin{array}{l}\text { Framed Plasterboard } \\
\text { Partition }\end{array}$ & 0,1 \\
\hline 3 & Kolom Beton & Concrete Block Plaster & 0,01 \\
\hline 4 & Balok Beton & Concrete Block Plaster & 0,01 \\
\hline 5 & Balok Baja & Metal Deck & 0,1 \\
\hline 6 & Jendela & $\begin{array}{l}\text { Single Glazed Aluminium } \\
\text { Frame Blinds }\end{array}$ & 0,02 \\
\hline 7 & Lantai & $\begin{array}{l}\text { Concrete Floor Tiles } \\
\text { Suspended }\end{array}$ & 0,02 \\
\hline 8 & Plafond 1 & Plaster Joist Suspended & 0,1 \\
\hline 9 & Plafond 2 & Concrete Block Plaster & 0,01 \\
\hline 10 & Plafond 3 & Metal Deck & 0,1 \\
\hline 11 & Pintu & Solid Core Pine Timber & 0,08 \\
\hline 12 & Papan tulis & Plywood & 0,25 \\
\hline 13 & Lemari dan meja & Plywood & 0,25 \\
& komputer & & \\
\hline & & &
\end{tabular}

Sumber: Ecotect

Berdasarkan perhitungan dengan menggunakan Ecotect, waktu dengung ruangan Wastu 1 kondisi eksisting adalah sebesar 1,45 detik. Nilai tersebut masih cukup tinggi karena waktu dengung optimal untuk ruangan kuliah tersebut adalah sebesar 0,78 detik. 


\subsection{EKSPERIMEN 1}

Pada eksperimen 1 dilakukan perubahan bentuk dan material pada dinding dan plafond. Plafond rendah ditutup plafond akustik dengan model datar dan pada plafond tinggi ditutup gypsum dengan model datar juga (Gambar 7). Penggunakan plafond gypsum dan plafond akustik mengurangi ketinggian plafond sehingga mampu mengurangi volume ruangan. Kolom dan beberapa bagian dinding ditutup oleh cork. Penutupan cork diharapkan mampu menurunkan waktu dengung karena nilai $\alpha$ cork lebih tinggi daripada brick plaster dan concrete block plaster (Tabel 1 dan 2). Waktu dengung eksperimen 1 adalah sebesar 0,83 detik. Nilai tersebut mempunyai selisih 0,05 detik dari waktu dengung optimal yang mempunyai nilai waktu dengung sebesar 0,78 detik.

Tabel 2.

Material Properties pada Eksperimen 1

\begin{tabular}{cllc} 
No & Elemen Bangunan & \multicolumn{1}{c}{ Jenis Material } & $\begin{array}{c}\text { a pada Frekuensi } \\
500 \mathrm{~Hz}\end{array}$ \\
1 & Plafond tinggi & $\begin{array}{l}\text { Plaster Joist } \\
\text { Suspended (Gypsum) }\end{array}$ & 0,1 \\
\hline 2 & Plafond rendah & $\begin{array}{l}\text { Acoustic Tile } \\
\text { Suspended }\end{array}$ & 0,47 \\
\hline 3 & Panel & Cork & 0,25 \\
\hline
\end{tabular}

Sumber: Ecotect

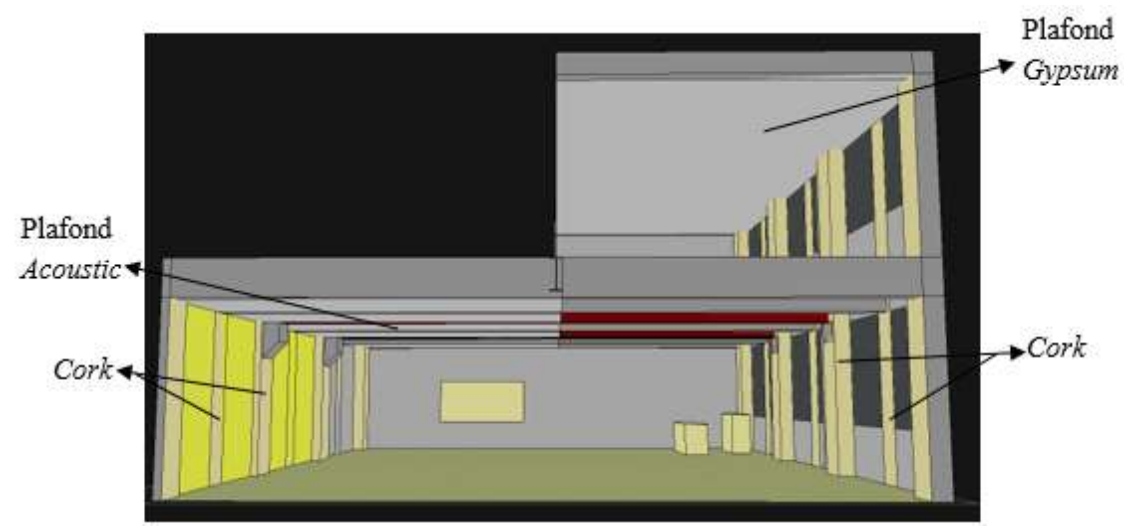

Gambar 7.

Modelling Eksperimen 1 dengan Ecotect

Sumber: Ecotect, November 2019

\subsection{EKSPERIMEN 2}

Pada eksperimen 2 dilakukan perubahan model dinding. Penambahan lapisan acoustic dan cork pada dinding sisi kiri dan penebalan dinding cork sebesar $10 \mathrm{~cm}$ pada dinding sisi kanan (Gambar 8). Plafond 
rendah ditutup gypsum dan plafond tinggi tidak dilakukan perubahan jadi tetap dag beton (concrete). Hasil perhitungan waktu dengung pada eksperimen 2 adalah sebesar 0,91 detik. Nilai tersebut mempunyai selisih 0,13 detik dari waktu dengung optimal ( 0,78 detik).

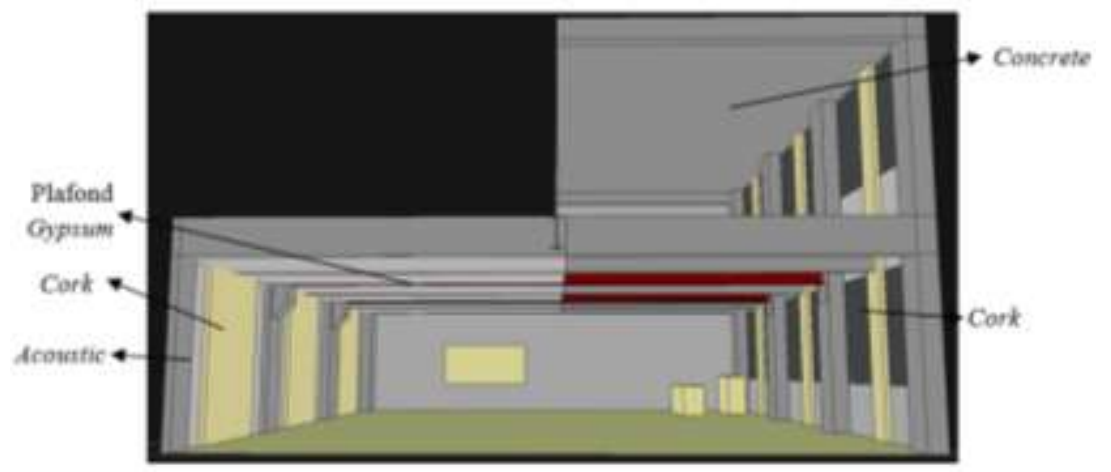

Gambar 8.

Modelling Eksperimen 2 dengan Ecotect

\subsection{EKSPERIMEN 3 Sumber: Ecotect, November 2019}

Perubahan yang signifikan pada bentuk plafond dilakukan pada eksperimen ketiga. Plafond tinggi dibuat model drop ceiling (kedalaman 34,8 $\mathrm{cm}$ ) dengan material gypsum dan acoustic (Gambar 9). Nilai a plafond akustik adalah 0,47 . Nilai tersebut cukup besar untuk mengurangi waktu dengung. Plafond rendah ditutup gypsum dengan model datar. Dinding depan dan dinding belakang ditutup oleh lapisan frame plywood partition yang mempunyai nilai $\alpha$ cukup besar, yaitu 0,07 . Jika dibandingkan dengan dinding bata (brick plaster) yang mempunyai a sebesar 0,02 maka penggunaan frame plywood partition mampu mengurangi waktu dengung.

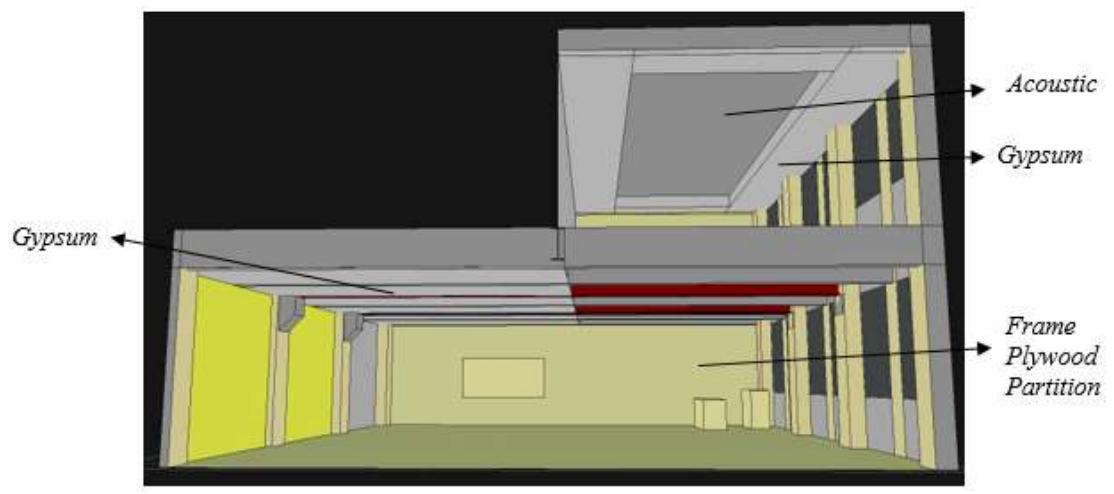

Gambar 9.

Modelling Eksperimen 3 dengan Ecotect

Sumber: Ecotect, November 2019 
Hasil perhitungan menunjukkan waktu dengung pada eksperimen ketiga adalah sebsar 0,89 detik. Nilai tersebut mempunyai selisih 0,11 detik jika dibandingkan dengan waktu dengung optimal (0,78 detik).

\subsection{EKSPERIMEN 4}

Pada eksperimen 4, plafond tinggi dibuat pola grid (dimensi $145 \times 145$ $\mathrm{cm}$ ) yang mempunyai perbedaan ketinggian sebesar $15,2 \mathrm{~cm}$ dengan penggunaan material gypsum dan akustik secara berselang-seling (Gambar 10 dan 11). Plafond rendah dibuat datar dengan penutup gypsum. Dinding depan dibuat pola horisontal timbul tenggelam dengan material acoustic dan cork. Semua kolom ditutup cork. Hasil perhitungan waktu dengung pada eksperimen 4 adalah sebesar 0,72 detik. Nilai itu mempunyai selisih 0,06 detik dari waktu dengung optimal (0,78 detik).

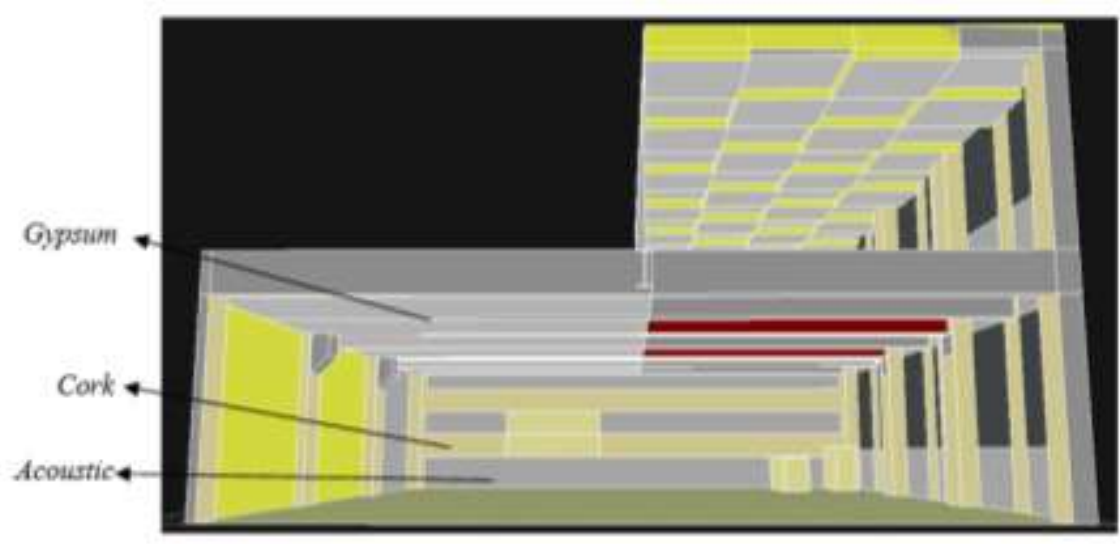

Gambar 10.

Modelling Eksperimen 4 dengan Ecotect

Sumber: Ecotect, November 2019

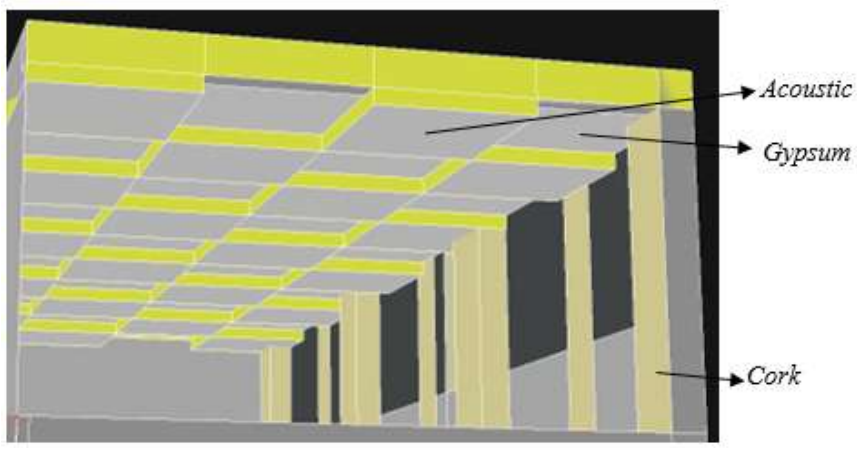

Gambar 11.

Model Grid pada Plafond Tinggi dengan Ecotect

Sumber: Ecotect, November 2019 


\subsection{PERBANDINGAN WAKTU DENGUNG (RT) KONDISI EKSISTING DAN EKSPERIMEN DENGAN WAKTU DENGUNG OPTIMAL}

Berdasarkan perbandingan nilai waktu dengung hasil eksperimen dengan waktu dengung optimal untuk ruang Wastu 1 maka model plafond dan dinding yang terbaik adalah eksperimen 1 (Gambar 12 dan tabel 3). Peringkat terburuk untuk model eksperimen adalah eksperimen 2.

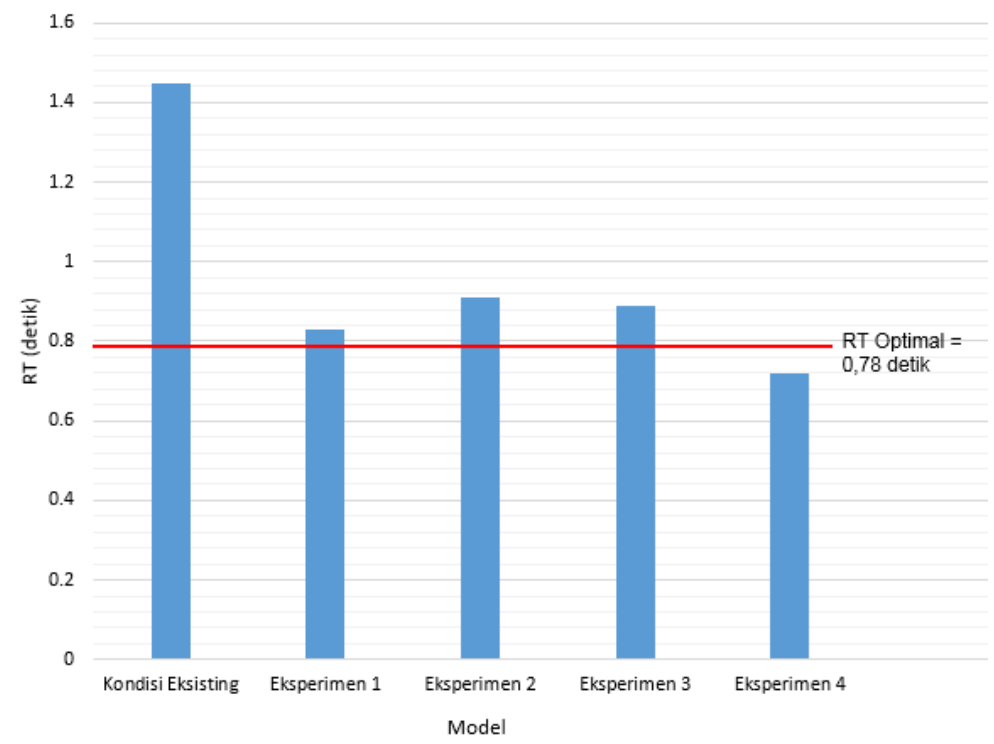

Gambar 12.

Perbandingan Waktu Dengung (RT)

Sumber: Ecotect, November 2019

Tabel 3.

Perbandingan Waktu Dengung (RT) Kondisi Eksisting dan Eksperimen dengan Waktu Dengung Optimal

\begin{tabular}{clccc} 
No & \multicolumn{1}{c}{ Model } & RT (Detik) & $\begin{array}{c}\text { Selisih RT } \\
\text { dengan RT } \\
\text { Optimal (0,78 } \\
\text { detik) }\end{array}$ & Peringkat \\
\hline 1 & $\begin{array}{l}\text { Kondisi } \\
\text { Eksisting }\end{array}$ & 1,45 & 0,67 detik & 5 \\
\hline 2 & Eksperimen 1 & 0,83 & 0,05 detik & 1 \\
\hline 3 & Eksperimen 2 & 0,91 & 0,13 detik & 4 \\
\hline 4 & Eksperimen 3 & 0,89 & 0,11 detik & 3 \\
\hline 5 & Eksperimen 4 & 0,72 & 0,06 detik & 2 \\
\hline
\end{tabular}

Sumber: Perhitungan Ecotect, November 2019 
Model eksperimen 1 menggunakan model plafond datar dengan material gypsum pada plafond tinggi dan material akustik pada plafond rendah. Semua kolom pada eksperimen 1 ditutup panel cork. Selain itu di antara dua kolom juga ditambahkan panel cork dengan lebar $62 \mathrm{~cm}$. Nilai $\alpha$ yang cukup besar pada plafond akustik dan panel cork pada eksperimen 1 mampu menurunkan waktu dengung sehingga mendekati waktu dengung optimal.

\section{KESIMPULAN}

Waktu dengung merupakan salah satu parameter untuk mengukur kualitas akstik suatu ruangan. Faktor-faktor yang mempengaruhi waktu dengung adalah volume ruangan, luas permukaan elemen ruangan, dan koefisien absorbsi bunyi ( $\alpha$ ). Waktu dengung optimal berdasarkan perhitungan Sabine pada ruangan Wastu 1 sebesar 0,78 detik. Berdasarkan perhitungan dengan menggunakan Ecotect, waktu dengung kondisi eksisting adalah 1,45 detik. Eksperimen dilakukan sebanyak 4 kali untuk memperbaiki waktu dengung. Perubahan bentuk dan material dinding dan plafond diatur agar diperoleh waktu dengung yang mendekati optimal. Hasil penelitian ini menunjukkan bahwa model plafond datar dengan material gypsum dan acoustic dan penambahan lapisan cork pada kolom dan dinding paling mampu memperbaiki waktu dengung.

\section{DAFTAR PUSTAKA}

Doelle, L.L. (1986), “Akustika Lingkungan”, Erlangga, Bekasi.

Groat, Linda dan David, Wang, (2002), "Architectural Research Methods", Edisi kedua, John Wiley \& Sons, Inc., United States of America

Kurniasih Sri. (2018), "Analisis Waktu Dengung pada Gedung Balai Sarbini", Jurnal AGORA, Volume 16, Nomor 2, Hal 82-91.

McMullan, Randall. (2007), Environmental Science in Building, Edisi Keenam, Palgrave Macmillanm, UK.

Ola, F.B. (2015), "Aplikasi Variabel Penyerap Bunyi Sederhana untuk Waktu dengung Frekuensi Menengah Atas pada Auditorium Fakultas Kedokteran UGM", Jurnal Arsitektur KOMPOSISI, Volume 11, Nomor 2, Hal 1-8.

Sabtalistia, Y.A. (2016), 'Pengaruh Bentuk Plafon terhadap Waktu Dengung (Reverberation Time), Prosiding Seminar Nasional Teknologi dan Sains (SNTS), Jakarta, 23-24.

Templeton Duncan. (1997), Acoustics Built Environment, Edisi Kedua, Architectural Press., Oxford. 